\title{
The Association of Antioxidant Status of Red Blood Cells in Patients with Type 2 Diabetes and in Patients with Complications of Diabetes and Its Comparison with That of Healthy Subjects
}

\author{
Chethan Subramanya ${ }^{1}$ \\ ${ }^{1}$ Department of General Medicine, K.S. Hegde Medical Academy, \\ Nitte Deemed to Be University, Deralakatte, Mangalore, Karnataka, India.
}

\section{ABSTRACT}

\section{BACKGROUND}

Oxidative stress plays a role in the pathogenesis of type 2 diabetes either by affecting insulin secretion or increasing insulin resistance. Oxidative stress is dealt by the body with the help of several antioxidant systems. The antioxidant levels in disorders causing oxidative stress such as diabetes mellitus are found to be low. Total antioxidant capacity (TAC), superoxide dismutase (SOD) and glutathione peroxide (GPx) levels are found to be depleted in diabetic groups when compared to control group comprising of healthy individuals. The activities of SOD and GPx are significantly low in diabetic patients. This study was conducted to determine the total antioxidant capacity and levels of antioxidants such as SOD and GPx in patients with type 2 diabetes and association between antioxidant levels and type 2 diabetics as well as type 2 diabetes with its associated complications.

\section{METHODS}

The study population comprised of 150 individuals, 50 subjects belonging to each subgroup of type 2 diabetics, and its associated complications and healthy subjects. The study was conducted in a tertiary care centre in Mangalore, Karnataka from September 2016 to December 2016. The antioxidant capacity of RBC, fasting blood levels of SOD and GPx were estimated by phospho molybdenum method. Nitroblue tetrazolium (NBT) reduction method and Rotruck method were also used.

\section{RESULTS}

The total antioxidant capacity, SOD and GPx were lower among diabetics and diabetic patients with complications as compared to normal nondiabetic subjects.

\section{CONCLUSIONS}

There is no significant difference in oxidative stress between patients with and without chronic complications of diabetes.

\section{KEY WORDS}

Antioxidant Levels, Glutathione Peroxidase, Oxidative Stress, Superoxide Dismutase, Nitroblue tetrazolium Reduction
Corresponding Author: Dr. Chethan Subramanya, S/o Dr. B. Shyama,

Post Box No. 10, Puttur,

Dakshina Kannada - 574201,

Karnataka, India.

E-mail: chethansub1985@gmail.com

DOI: $10.14260 /$ jemds/2021/176

How to Cite This Article:

Subramanya $C$. The association of antioxidant status of red blood cells in patients with type 2 diabetes and in patients with complications of diabetes, and its comparison with that of healthy subjects. J Evolution Med Dent Sci 2021;10(11): 825828, DOI: 10.14260/jemds/2021/176

Submission 23-11-2019,

Peer Review 23-01-2021,

Acceptance 30-01-2021,

Published 15-03-2021.

Copyright (C) 2021 Chethan Subramanya et al. This is an open access article distributed under Creative Commons Attribution License [Attribution 4.0 International (CC $B Y 4.0)]$ 


\section{BACKGROUND}

Diabetes mellitus is a chronic metabolic disorder characterised by high levels of blood sugar (hyperglycaemia). The defect lies in insulin secretion or action resulting in impaired metabolism of carbohydrates, lipids and proteins which lead to long term health complications.1,2 According to 2015 estimates, it was noted that 415 million people had diabetes worldwide, out of which $90 \%$ of the cases comprised of type 2 diabetes mellitus. ${ }^{2-5}$

Recent studies suggest that in addition to physical inactivity, obesity and other major risk factors, oxidative stress also plays a role in the pathogenesis of type 2 diabetes either by effecting insulin secretion or increasing resistance to insulin. ${ }^{6}$ Long term uncontrolled hyperglycaemia leads to damage, dysfunction and eventually failure of various organs such as eye (diabetic retinopathy), kidneys (diabetic nephropathy), nerves (diabetic neuropathy) and heart (myocardial infarction). ${ }^{7-8}$

Hyperglycaemia is known to increase oxidative stress. Oxidative stress occurs as a result of imbalance between the systemic manifestation of reactive oxygen species and the body's ability to detoxify the reactive oxygen species or to repair the resulting damage. ${ }^{9}$ Three major mechanisms responsible for hyperglycaemia induced oxidative stress are identified. Reactive oxygen species produced by the proton electromechanical gradient generated by the mitochondrial electron transport chain resulting in increased production of superoxide is one of the mechanisms. ${ }^{10}$

In another mechanism, free glucose undergoes autoxidation in a transition metal catalysed process resulting in the production of superoxide anion and hydrogen peroxide. ${ }^{11}$ Transition metal catalysis the autoxidation of protein bound. Amadori products producing superoxide, hydroxyl radicals and dicarbonyl compounds is another known mechanism. ${ }^{12}$ The oxidative stress is dealt by cells by means of several enzymatic and non-enzymatic antioxidant systems that work together. Studies have shown that the level of antioxidants in diabetics is reduced.

There is evidence to suggest that plasma / serum antioxidant status is reduced along with specific antioxidants like ascorbic acid and vitamin $\mathrm{E}$ together with an increase in free radicals in type 2 diabetics. Catalase, superoxide dismutase and glutathione peroxidase activity is found to be reduced in diabetics. ${ }^{10}$ This study was conducted to evaluate the blood levels of several antioxidants in patients with type 2 diabetes and to understand the association between antioxidant levels and glycaemic control among type 2 diabetics as well as type 2 diabetics with complications.

\section{Objectives}

- To estimate the total antioxidant capacity of RBC and fasting blood levels of SOD (superoxide dismutase), Gpx (glutathione peroxide) in RBC in type 2 diabetics, type 2 diabetics with complications and healthy subjects.

- $\quad$ To compare the above parameters between type 2 diabetics, type 2 diabetics with complications and healthy individuals of same age.

\section{METHODS}

This study was designed as a case control study. Ethical clearance was obtained from institutional ethics committee, KSHEMA. Study subjects were recruited from K.S. Hegde Charitable Hospital, Deralakatte, Mangalore and the study was carried out in the Central Research Laboratory, K.S. Hegde Medical Academy. Patients diagnosed with type 2 diabetes mellitus, patients with type 2 diabetics and its complications and healthy subjects above 18 years were included in the study. Patients willing to give the consent were also included. Subjects with use of drugs affecting lipid profile and antioxidant supplementation were excluded from the study. The study population comprised of Group I: 50 healthy individuals, Group II: 50 type 2 diabetes mellitus patients, Group III: 50 type 2 diabetes mellitus patients with complications. Total 150 subjects in study population. Patients of both sexes were included in the study. Informed consent was obtained from the study participants. The sample size was taken based on the convenience of the study.

Taking aseptic precautions, approximately $3 \mathrm{ml}$ of venous blood was collected in ethylenediamine tetraacetic acid (EDTA) tubes. Plasma was used to determine total antioxidant capacity and whole blood was used for estimating the levels of superoxide dismutase and glutathione peroxidase.

\section{Estimation of the Total Antioxidant Capacity by Phosphomolybdenum Method ${ }^{13}$}

$100 \mu \mathrm{L}$ of the plasma sample was pipetted out into a clean test tube and $100 \mu \mathrm{L}$ of $5 \%$ trichloroacetic acid (TCA) was added to it to precipitate out the proteins in the sample, the mixture was then allowed to stand for about five minutes and centrifuged. $100 \mu \mathrm{L}$ of the clear supernatant was transferred into a clean test tube and $1 \mathrm{~mL}$ of TAC reagent was added to it and the mixture was then incubated in water bath at 90 degree $\mathrm{C}$ for 90 minutes. A blank was also maintained simultaneously by substituting $100 \mu \mathrm{L}$ of water instead of sample in the reaction mixture. Following the incubation, the reaction mixture was cooled and the optical density of the greenish to bluish colour formed was read at $695 \mathrm{~nm}$ against blank.

\section{Estimation of Superoxide Dismutase by NBT Reduction Method ${ }^{14}$}

$100 \mu \mathrm{L}$ of RBC lysate is further diluted by the addition of 400 $\mu \mathrm{L}$ of $0.05 \mathrm{M}$ phosphate buffer to get a final erythrocyte dilution of 1:20. Test: $2.5 \mathrm{~mL}$ methionine, $0.3 \mathrm{~mL}$ riboflavin, $0.1 \mathrm{~mL} \mathrm{NBT}$ and $0.1 \mathrm{~mL}$ RBC lysate. Control: $2.5 \mathrm{~mL}$ methionine, $0.3 \mathrm{~mL}$ riboflavin, $0.1 \mathrm{~mL}$ phosphate buffer $0.05 \mathrm{M} \mathrm{(pH} \mathrm{7.8)} \mathrm{and} 0.1 \mathrm{~mL}$ RBC lysate. Standard: $2.5 \mathrm{~mL}$ methionine, $0.3 \mathrm{~mL}$ riboflavin, 0.1 mL NBT and $0.1 \mathrm{~mL}$ phosphate buffer $0.05 \mathrm{M}$ (pH 7.8). Blank: $2.5 \mathrm{~mL}$ methionine, $0.3 \mathrm{~mL}$ riboflavin and $0.2 \mathrm{~mL}$ phosphate buffer $0.05 \mathrm{M},(\mathrm{pH} 7.8)$

\section{Glutathione Peroxidase 15}

$0.4 \mathrm{ml}$ of buffer, $0.1 \mathrm{ml}$ sodium azide, $0.2 \mathrm{ml}$ of reduced glutathione, $0.5 \mathrm{ml}$ of enzyme extract and $0.1 \mathrm{ml}$ of hydrogen peroxide into a test tube was pipetted out. The final volume to $2 \mathrm{o} \mathrm{ml}$ with distilled water was made up. The tube was 
incubate at 37 degree $\mathrm{C}$ for 30 minutes. $0.5 \mathrm{ml}$ of $10 \%$ TCA was added to stop the reaction. To determine the unused / residual glutathione content, the content was centrifuged, the supernatant was saved and $0.5 \mathrm{ml}$ of this was added to $2 \mathrm{ml}$ of disodium hydrogen phosphate and $0.25 \mathrm{ml}$ of $55^{\text {'-dithiobis-2- }}$ nitrobenzoic acid (DTNB) reagent. The absorbance was read at $412 \mathrm{~nm}$. A blank was set with only disodium hydrogen phosphate and DTNB reagent.

\section{Statistical Analysis}

Data was collected and statistically analysed by using Statistical Package for the Social Sciences (SPSS) software. The collected information was summarised using the descriptive statistics such as mean, standard deviation, frequency and percentage. To compare the outcome measures between control, type 2 diabetes and type 2 diabetes mellitus with complication subjects, one-way analysis of variance (ANOVA) test was used. Comparison between the groups was done using Tukey's HSD test (honestly significant difference) and MannWhitney test. The $\mathrm{P}$ value $<0.05$ was considered to be statistically significant.

\section{RESULTS}

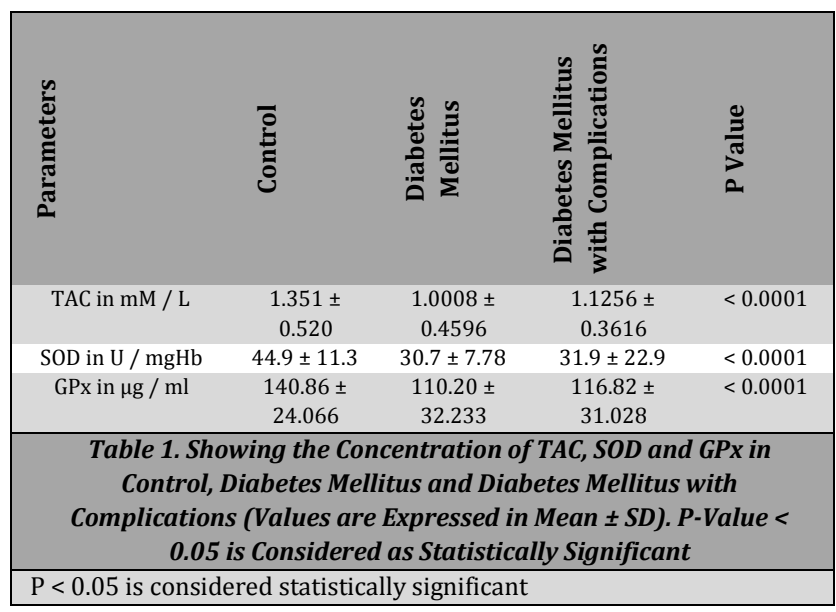

\begin{tabular}{|c|c|c|c|c|c|c|}
\hline Control & & DM & & $\begin{array}{l}\text { DM with } \\
\text { Complications }\end{array}$ & & $\begin{array}{l}\text { Kruskal } \\
\text { Wallis P } \\
\text { Value }\end{array}$ \\
\hline Median & IQR & Median & IQR & Median & IQR & \\
\hline 46.5 & $\begin{array}{c}39.33 \text { to } \\
52.5\end{array}$ & 28 & $\begin{array}{l}25.57 \\
\text { to } \\
36.42\end{array}$ & 16 & $\begin{array}{l}11.01 \\
\text { to } \\
53.05\end{array}$ & $<0.001$ \\
\hline \multicolumn{7}{|c|}{$\begin{array}{c}\text { Table 2. Comparison of SOD between the Groups } \\
\text { Using Kruskal-Wallis Test }\end{array}$} \\
\hline \multicolumn{7}{|c|}{$\begin{array}{l}\text { Since the Kruskal-Wallis } \mathrm{P} \text { value was }<0.005 \text {, there was a difference in } \\
\text { median SOD levels among the subjects. } \\
\mathrm{P}<0.05 \text { is considered statistically significant }\end{array}$} \\
\hline
\end{tabular}

\section{DISCUSSION}

Diabetes is a chronic metabolic state characterised by hyperglycaemia. Hyperglycaemia is known to cause oxidative stress by the synthesis of reactive oxygen species (ROS) which is indicated by their elevated values. On the other hand, the antioxidant levels in diabetics is reduced leading to an imbalance between oxidative stress and body's defense against it. 1,2

In our study, levels of markers of anti-oxidant levels were quantified in normal, diabetic patients and diabetic patients with complications. Total antioxidant capacity (TAC), superoxide dismutase (SOD), glutathione peroxidase (GPx) levels were evaluated in the above patients. The results of our study showed that TAC was lower among diabetics and diabetic patients with complications as compared with normal non diabetic subjects. The values of glutathione peroxidase (GPx) was also found to be lower among diabetics and diabetic patients with complications as compared to normal subjects. Comparison of SOD levels among three groups also showed lower levels of SOD among diabetics and diabetics with complications than normal subjects. No significant differences in oxidative levels markers were found between patients with and without chronic complications of diabetes.

In the study, markers of antioxidant levels in patients with type 2 diabetes by Gawlik at al. ${ }^{16}$ it was found that, in subjects with type 2 diabetes, significantly lower levels of glutathione peroxidase and higher levels of glutathione reductase both in plasma and hemolysate were found. Total antioxidant capacity of plasma assessed by the ferric reducing ability of plasma (FRAP), serum uric acid and gamma-glutamyl transferase high (GGT) involved in antioxidant defense, were significantly higher in patients with diabetes

A study on total antioxidant capacity, superoxide dismutase and glutathione peroxidase in diabetic patients by Rahbani et al.,17 it was found that, compared with the control, the total antioxidant capacity was depleted in two diabetic groups. The activities of SOD and GPX were significantly low in two types of diabetic patients.

In another study conducted by C. Kornhauser et al.,18 decreased levels of glutathione peroxidase and glutathione reductase was found in type 2 diabetics. Similar results showing reduced levels of glutathione peroxidase and superoxide dismutase was found in a study by Kumawat et al. ${ }^{19}$

\section{CONCLUSIONS}

There is significant deficiency of markers of antioxidant levels in diabetics as well as diabetics with its complications. Hence, these markers could play a role in early identification of individuals at risk of diabetes mellitus and those individuals at risk of developing its complications. It also indicates that there is scope for research into the benefits of antioxidant supplementation in individuals at risk of developing diabetes in general population and diabetic patients at risk of developing its chronic complications.

Data sharing statement provided by the authors is available with the full text of this article at jemds.com.

Financial or other competing interests: None.

Disclosure forms provided by the authors are available with the full text of this article at jemds.com. 


\section{REFERENCES}

[1] Gezginci - Oktayoglu S, Basaraner H, Yanardag R, et al. The effects of combined treatment of antioxidants on the liver injury in STZ diabetic rats. Dig Dis Sci 2009;54(3):538-46.

[2] American Diabetes Association. Diagnosis and classification of diabetes mellitus. Diabetes Care 2010;33(Suppl 1):S62-S9.

[3] IDF. International Diabetes Federation. Update 2015.

[4] Melmed S, Polonsky K, Larsen RP, et al. Williams textbook of Endocrinology. 12th edn. Philadelphia: Elsevier/Saunders 2011: p. 1371-435.

[5] Shi Y, Hu FB. The global implications of diabetes and cancer. Lancet 2014;383(9933):1947-8.

[6] Brownlee M. Biochemistry and molecular cell biology of diabetic complications. Nature 2001;414(6865):813-20.

[7] Tesfaye S, Gill G. Chronic diabetic complications in Africa. Afr J Diabetes Med 2011;19:4-8.

[8] Chintan AP, Nimish LP, Nayana B, et al. Cardiovascular complication of diabetes mellitus. J Appl Pharm Sci 2011;4:1-6.

[9] Montonen J, Knekt P, Jarvinen R, et al. Dietary antioxidant intake and risk of type 2 diabetes. Diabetes Care 2004;27(2):362-6.

[10] Nishikawa T, Edelstein D, Du XL, et al. Normalizing mitochondrial superoxide production blocks three pathways of hyperglycaemic damage. Nature 2000;404(6779):787-90.

[11] Baynes JW, Thorpe SR. Role of oxidative stress in diabetic complications: a new perspective on an old paradigm. Diabetes 1999;48(1):1-9.
[12] Wolff SP. Diabetes mellitus and free radicals. Free radicals, transition metals and oxidative stress in the aetiology of diabetes mellitus and complications. Br Med Bull 1993;49(9):642-52.

[13] Prieto P, Pineda M, Aguilar M. Spectrophotometric quantitation of antioxidant capacity through the formation of phosphomolybdenum complex: specific application to the determination of vitamin E. Anal Biochem 1999;269(2):337-41.

[14] Beaurchamp C, Fridovich I. Superoxide dismutase improved assay applicable to acrylamide gels. Anal Biochem 1971;44(1):276-87.

[15] Rotruck JT, Pope AL, Ganther HE, et al. Selenium: biochemical role as a component of glutathione peroxidase purification and assay. Science 1973;179(4073):588-98.

[16] Gawlik K, Naskalski JW, Fedak D, et al. Markers of antioxidant defense in patients with type 2 diabetes. Oxid Med Cell Longev 2016;2016:2352361.

[17] Rahbani-Nobar ME, Rahimi-Pour A, Rahbani-Nobar M. et al. Total antioxidant capacity, superoxide dismutase and glutathione peroxidase in diabetic patients. Medical Journal of Islamic Academy of Sciences 1999;12(4):10914.

[18] Kornhauser C, Garcia-Ramirez JR, Wrobel K, et al. Serum selenium and glutathione peroxidase concentrations in type 2 diabetes mellitus patients. Prim Care Diabetes 2008;2(2):81-5.

[19] Kumawat M, Singh N, Singh S. Status of antioxidant enzymes and lipid peroxidation in type 2 diabetes mellitus with neuropathy. Annals of Neurosciences 2005;12(3):49-52. 